\title{
Partial cecum resection using endostapler in acute complicated appendicitis with appendiceal base necrosis
} \author{
Mehmet Karabulut ${ }^{1}$ \\ ${ }^{1}$ Bakırkoy Dr. Sadi Konuk Training and Research Hospital, Istanbul, Turkey \\ IIstanbul Provincial Health Directorate, Turkey
}

Serhan Yilmaz ${ }^{1}$, Turgut Donmez ${ }^{1}$, Sina Ferahman ${ }^{1}$, Cevher Akarsu$^{1}$, Sezer Bulut ${ }^{1}$, Halim Ozcevik ${ }^{2}$, Husnu Aydin ${ }^{1}$,

Videosurgery Miniinv 2022; 17 (1): 143-149

DOI: https://doi.org/10.5114/wiitm.2021.105574

\begin{abstract}
Introduction: The method of stump closure is controversial in complicated patients, especially with appendix base necrosis or perforation.

Aim: To evaluate the efficacy and safety of partial cecum resection technique with an endostapler in patients with appendix base necrosis or perforation.

Material and methods: Thirty-six patients who underwent laparoscopic partial cecum resection due to appendix base necrosis or perforation between 2015 and 2020 were retrospectively analyzed. In acute complicated appendicitis with appendiceal base necrosis or perforation, it was performed by laparoscopic partial cecum resection using an endostapler within a safe surgical margin. Demographic characteristics, duration of operation, days of hospital stay, and intra- and post-operative complications were evaluated.

Results: The mean age of the patients is $42.72 \pm 16.69$, female/male ratio was $19 / 17$ (52.8\%/47.2\%). No intraoperative complications developed. Mean operative time and hospital stay were $104.75 \pm 34.96,4.58 \pm 2.82$ days, respectively. Post-operative complications developed in 5 (13.7\%) patients. One of them was wound infection (2.7\%), 2 of them were ileus (5.5\%) and 2 patients had an intraabdominal abscess (5.5\%). Stapler line leak was not observed in any of the patients.

Conclusions: The use of an endostapler in laparoscopic appendectomy is a safe and effective technique in cases where appendix base necrosis, appendix perforation or severe inflammation affects the base of the cecum.
\end{abstract}

Key words: acute complicated appendicitis, partial cecum resection, endostaples.

\section{Introduction}

Acute appendicitis (AA) is the most common emergency surgical disease, with a reported rate of $8 \%$ in all lifetime. Compared to open appendicitis (OA), laparoscopic appendectomy (LA) provides better diagnostic accuracy, less analgesic use, shorter hospital stay, earlier return to daily activities and a lower rate of wound infection [1-4]. Controversial evidence exists regarding the laparoscopic approach in patients with complicated acute appendicitis due to the higher rate of surgical complications [3, 4]. Benefits of treating acute appendicitis complicated with LA include extensive examination of the peritoneal cavity, debridement, irrigation and lavage under direct visualization, avoidance of large abdominal incisions, and fewer pulmonary complications [5].

There are many studies on the closure of the appendix stump in uncomplicated and complicated appendicitis, and there is no consensus in the litera-

\section{Address for correspondence}

Assoc. Prof. Turgut Donmez, Bakırkoy Dr. Sadi Konuk Training and Research Hospital, Istanbul, Turkey, phone: +90 5347400967,

e-mail: surgeont73@hotmail.com 
ture on the advantages of the techniques over each other [6-9]. Although the methods of closure of the appendix stump with metal clips, hem-o-lock clips, endoloop, intracorporeal knot and endostapler in complicated appendicitis are reported in the literature $[8,10,11]$, the technical issue of stump closure in patients with necrosis or perforation in the base of the appendix is still controversial [11].

\section{Aim}

In our study, we aimed to evaluate the efficacy and reliability of partial cecum resection technique with endostapler in patients with appendiceal base necrosis or perforation.

\section{Material and methods}

Between January 2015 and October 2020 with the diagnosis of appendix base necrosis or perforation a total of 36 patients who underwent laparoscopic partial cecum resection were reviewed retrospectively. Appendix base necrosis was evaluated according to the laparoscopic staging of acute appendicitis disease described by Gomes et al. [11] (Table I). Patients with complicated acute appendicitis aged $18-80$ years with peri-operative Gomes Stage 3B were included in the study. Patients with uncomplicated appendicitis, incomplete clinical-demographic data, incompatible with treatment and inability to follow up were excluded from the study. Informed consent forms were obtained from all patients. Local ethics committee approval was obtained (no: 2019-02-10).

Table I. Gomes staging in laparoscopic appendectomy

\begin{tabular}{|lr|}
\hline Stage & Laparoscopic finding \\
\hline 0 & Normal appendix \\
\hline 1 & Hyperemic and edematous appendix \\
\hline 2 & Appendix with fibrin exudate \\
\hline $3 \mathrm{~A}$ & Necrosis or perforation in the base of the \\
& dix \\
\hline $3 \mathrm{~B}$ & appendix \\
\hline $4 \mathrm{~A}$ & Abscess \\
\hline $4 \mathrm{~B}$ & Local peritonitis \\
\hline 5 & Generalized peritonitis \\
\hline
\end{tabular}

Preoperative diagnosis was made by abdominal computed tomography (CT) in all patients. Demographic characteristics of the patients such as age, gender, body mass index (BMI), ASA scores, preoperative white blood cells (WBC) and C-reactive protein (CRP) values were recorded. The duration of operation, days of hospital stay and post-operative complications were evaluated. The operation time was evaluated as the time ( $\mathrm{min}$ ) from skin incision to skin closure. Intra-operative complications were evaluated as bleeding and iatrogenic injury. Wound infection was defined as edema, redness, or purulent discharge from the incision within 30 days after the operation. Intraabdominal abscess (IAA) diagnosis was made by CT after clinical suspicion. Inability to expel gas and stool 24-48 h post-operatively, abdominal distension, tenderness in abdominal examination findings, and the need for re-nasogastric tube decompression were defined as ileus. The duration of the operation, the rate of conversion to open surgery, duration of hospital stay, intraoperative complications, and stump leakage were used to evaluate the safety and efficacy of this technique. Operations were performed by surgeons who performed 50 or more laparoscopic appendectomies per year.

\section{Surgical technique}

All patients received $1 \mathrm{~g}$ of ceftriaxone prophylaxis after general anesthesia. Orogastric and Foley urinary catheters were inserted in all patients. After a $1 \mathrm{~cm}$ skin incision under the umbilicus, $12 \mathrm{~mm} \mathrm{Hg} \mathrm{CO}$ pneumoperitoneum was created with a Veress needle then a $10 \mathrm{~mm}$ trocar was inserted. With a 30-degree camera from the umbilical trocar $15 \mathrm{~mm}$ from the left lower quadrant and $5 \mathrm{~mm}$ from the suprapubic region were inserted under direct vision after exploration. The patient was placed in a Trendelenburg and 15-degree left lateral position. In complicated acute appendicitis cases with necrosis and perforation in the proximal part of the appendix and the base of the cecum (Photo 1 A), it was decided to perform partial cecum resection with an endostapler. The mesoappendix was divided by $10 \mathrm{~mm}$ bipolar tissue closure systems (LigaSure Valleylab, Boulder, CO). Partial cecum resection was performed from the superior part of the ileocecal junction with a $60 \mathrm{~mm}$ endo-GIA stapler (Medtronic, Medtronic Parkway, Minneapolis, MN) 

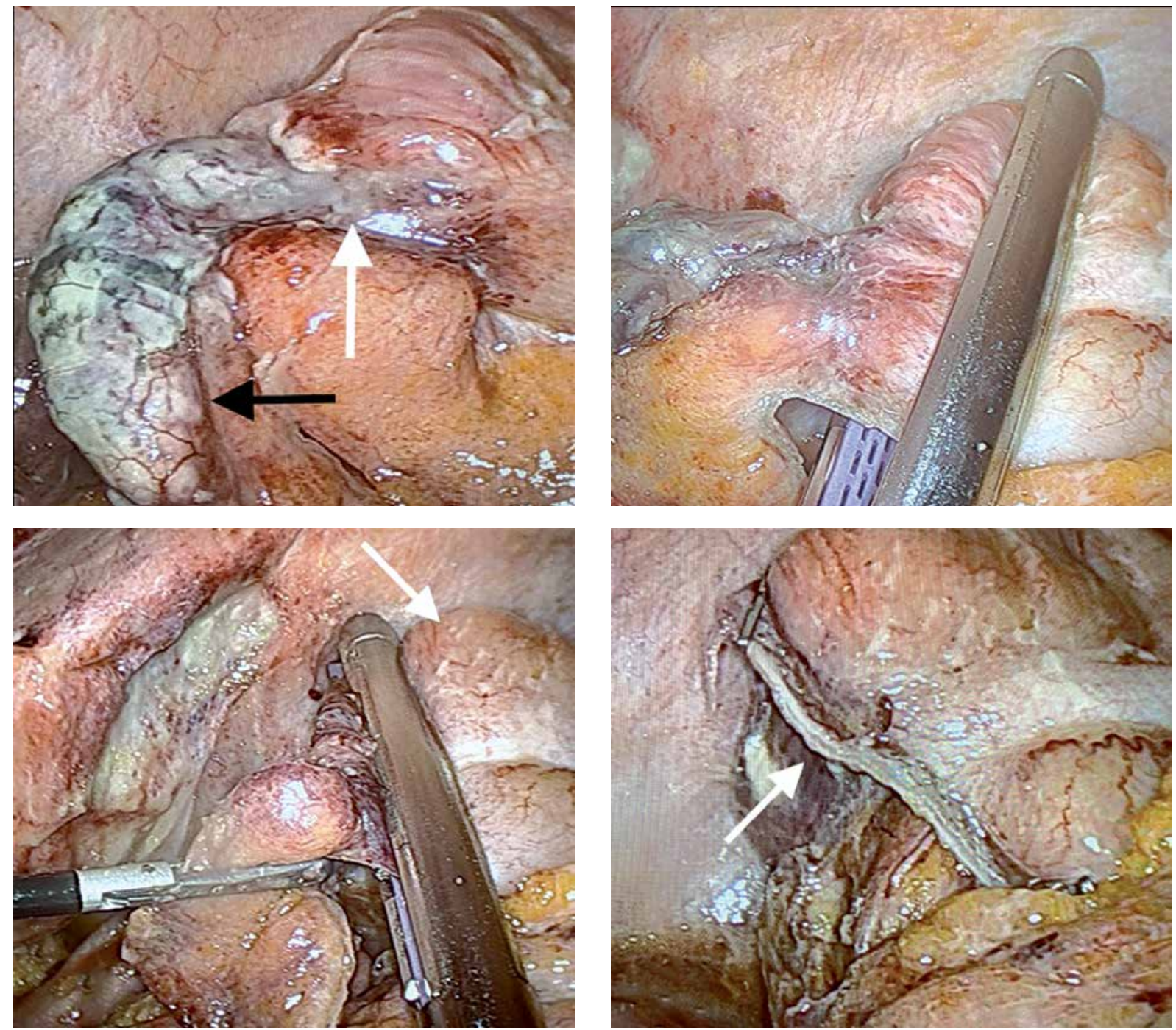

Photo 1. Intraoperative view. A - Appendix and cecum appearance in complicated acute appendicitis (Gomes 3B). Necrosis in the base of the appendix (white arrow) and necrotic appendix body (black arrow). B - Application of endostaples for partial cecal resection. C - Cutting the cecum from the non-inflamed section (white arrow) with endostapler. D - View of the stapler line (white arrow) in the cecum after resection

to include the root of the appendix with a safe surgical margin (Photos $1 \mathrm{~B}, \mathrm{C}$ ). The resection material was taken out of the abdomen with a specimen bag (EndoCatch; USSC, Norwalk, CT, USA). The stapler line in the cecum was checked after resection (Photo $1 \mathrm{D}$ ). In open appendectomies, after $1 \mathrm{~g}$ of ceftriaxone prophylaxis after general anesthesia, Orogastric and Foley urinary catheters were placed in all patients, and the abdomen was entered with a sub-umbilical median incision. Appendectomy was performed as in the laparoscopic technique. All patients were started orally at the $4^{\text {th }}$ hour post-operatively.

\section{Statistical analysis}

Frequency and percentage for categorical variables, mean and standard deviation values for continuous variables were given. All analyses were done with SPSS 22.0 for Windows (IBM SPSS Statistics for Windows, Version 22.0. Armonk, NY: IBM Corp.).

\section{Results}

The mean age of the patients is $42.72 \pm 16.69$ years (range: 18-83). Mean BMl was $26.23 \pm 4.09 \mathrm{~kg} / \mathrm{m}^{2}$. The female/male ratio was $19 / 17$ (52.8\%/47.2\%). Eight (22.2\%) patients were ASA 1, 24 (66.7\%) pa- 
tients were ASA 2, 3 (8.3\%) patients were ASA 3 and $1(2.8 \%)$ patient was ASA 4. Demographic data are presented in Table II.

Two (5.5\%) patients were converted to open appendectomy because of difficulty in exploration; no intraoperative complications developed. While the mean operative time was $104.75 \pm 34.96 \mathrm{~min}$, post-operative complications developed in $5(13.7 \%)$ patients. One of them was wound infection (2.7\%), 2 of them were ileus (5.5\%), and 2 (5.5\%) patients had an intraabdominal abscess. While 1 (2.7\%) patient with an intraabdominal abscess was treated with surgical drainage on the post-operative fourth day, other patients who developed complications were treated medically. Mean hospital stay was 4.58 \pm 2.82 days, while stapler line leak was not observed in any of the patients. Surgical results are shown in Table III.

Table II. Demographic data

\begin{tabular}{|c|c|}
\hline Parameter & Value \\
\hline Age & $42.72 \pm 16.69$ (range: $18-83)$ \\
\hline \multicolumn{2}{|l|}{ Gender, $n(\%)$ : } \\
\hline Female & $19(52.8)$ \\
\hline Male & $17(47.2)$ \\
\hline BMI $\left[\mathrm{kg} / \mathrm{m}^{2}\right]$ & $26.23 \pm 4.09$ \\
\hline \multicolumn{2}{|l|}{ ASA score, $n(\%)$ : } \\
\hline 1 & $8(22.2)$ \\
\hline 2 & $24(66.7)$ \\
\hline 3 & $3(8.3)$ \\
\hline 4 & $1(2.8)$ \\
\hline $\mathrm{WBC}\left[\times 10^{3} / \mathrm{mm}^{3}\right]$ & $18.914 \pm 43.27$ \\
\hline $\mathrm{CRP}[\mathrm{mg} / \mathrm{l}]$ & $9.45 \pm 5.13$ \\
\hline
\end{tabular}

Table III. Surgical results

\begin{tabular}{|c|c|c|}
\hline Variable & $N$ & $\%$ \\
\hline Conversion to open & 2 & 5.5 \\
\hline Complication: & 5 & 13.7 \\
\hline Wound infection & 1 & 2.7 \\
\hline Ileus & 2 & 5.5 \\
\hline $\begin{array}{l}\text { Intraabdominal } \\
\text { abscess }\end{array}$ & 2 & 5.5 \\
\hline Stump leakage & 0 & 0 \\
\hline Hospital stay [days] & $4.58 \pm 2.82$ & \\
\hline Operation time [min] & $104.75 \pm 34.96$ & \\
\hline
\end{tabular}

\section{Discussion}

Gangrenous and/or perforated appendicitis causing intraabdominal abscesses or peritonitis is called complicated appendicitis $[4,8,10,11]$. According to the classification defined by Gomes et al., Stage 3A (segmental necrosis/perforation), 3B (base necrosis/ perforation), 4A (abscess), 4B (local peritonitis) and 5 (generalized peritonitis) appendicitis are classified as complicated [10]. $20-30 \%$ of acute appendicitis cases appear as perforated appendicitis [12, 13].

Laparoscopic appendectomy is safe and effective in the treatment of complicated appendicitis [1-4, 14, 15]. Stump closure technique is directly related to post-operative complications in complicated appendicitis. It is obvious that the morbidity will decrease after a safe stump closure method. Therefore, there are many studies in the literature to determine the correct and effective technique. Metal clip, hemo-lock clips, endoloop, intracorporeal knot, extracorporeal knot, and endostapler methods have been widely applied and compared [8-10]. Although there are publications showing that titanium or polymeric clips are effective and safe in the closure of the appendix stump, these studies have not been performed in cases of complicated appendicitis [16, 17].

Matyja et al. [18] in a retrospective study comparing stump closure techniques stated that the use of staplers would be more appropriate in specific cases such as base necrosis detected preoperatively. In studies, it is argued that the use of a stapler or exposure to the base of the appendix is the best therapeutic method in cases of severe inflammation or necrosis [7, 19]. Also in an another retrospective study comparing stump closure methods in complicated appendicitis, intracorporeal suture and stapler techniques were used in the laparoscopic group; however, in the laparoscopic group, they stated that they used staplers in 3 cases with severe inflammation or necrosis at the base of the appendix [20].

Although there are a wide variety of stump closure techniques in complicated appendicitis, the two most common methods are endoloop and stapler [6, 21-25]. There are publications showing that the endoloop is not safe in appendix base perforations or when inflammation in the appendix affects the base of the cecum [26-29]. Poole argued that the use of staplers in advanced appendicitis reduced the incidence of post-operative stump leakage [30]. Comparing the laparoscopic and open technique in 
a prospective randomized controlled study involving 81 patients with complicated appendicitis, Taguchi et al. used a stapler as a method for closing the appendix stump in the laparoscopy group [31]. They thought that they avoided ligation in fragile and necrotic tissue in complicated appendicitis, and that the use of a stapler could decrease the rate of stump leakage. Gomes et al. in a prospective study of 186 patients emphasized that the operation is very difficult in stage 3B appendix and if the stapler is not used routinely, intracorporeal suture may be required depending on the experience of the surgical team. It has also been reported that specific comparative studies are needed for different stages of appendicitis [32]. Ceresoli et al. concluded that if inflammation and infection may affect the appendix base and cecum, the importance of safe stump closure technique in complicated appendicitis has been emphasized, and it has been concluded that the method depends on the surgeon, the state of the appendix macroscopically and the stage of inflammation, the accessibility and cost of the method [33].

Stump leakage is one of the most important factors determining the success of the operation after appendectomy. Considering that all patients included in our study had appendix base necrosis or perforation, no stump leakage was observed in any of our patients. Also, we did not experience any intraoperative complications. In our study, due to difficulty in exploration, 2 (5.5\%) patients were switched to open technique. Our success rate with laparoscopic technique was determined as $94.4 \%$.

When the operation time is evaluated in complicated appendicitis, different results are encountered. Comparing the most commonly used endoloop and stapler techniques, there are publications stating that the use of a stapler has a significantly shorter operation time [8, 25, 26], whereas others found that the endoloop has a significantly shorter operation time $[6,7]$. There are also publications showing that there is no significant difference in operative time between the two techniques [23]. Regardless of the stump closure technique, the mean operative times for different studies in the literature for laparoscopic treatment of complicated appendicitis were reported to be $73.1 \pm 25.6$ [3], 69.4 \pm 26.4 [10], $116.7 \pm 45.7$ [20], $120.6 \pm 17.7$ [34] and $84.6 \pm 34.5$ [31] $\mathrm{min}$. These differences in operation times can be explained by the different stages of diseases and the variability of the technique used.
We believe that the use of staplers will shorten the operation time in complicated appendicitis. In our study, the mean operation time was found to be $104.75 \pm 34.96 \mathrm{~min}$, and it is thought to be a reasonable time for stage $3 \mathrm{~B}$ appendicitis, which can be considered technically difficult.

Hospital stay in complicated appendicitis in the literature is reported by Katsuno et al. as $8.9 \pm 3.7$ [20], by Talha et al. as $6.2 \pm 1.6$ [34], by Taguchi et al. as $11.4 \pm 8.57$ [31] and by Dimitriou et al. as $5.2 \pm 1.5$ [35] days. In our study, the duration of hospital stay was $4.58 \pm 2.82$ days and was found to be shorter when compared with the literature. We think that it would be correct to explain this by our low rate of post-operative complications and, consequently, that patients can return to their daily lives after being discharged in a short time.

Post-appendectomy wound infections, intraabdominal abscesses (IAA), ileus and post-operative small bowel obstruction are among the complications that may be encountered. It is a fact that these complications can be prevented with the optimal stump closure method. Regardless of the technique of stump closure after laparoscopic treatment of complicated appendicitis, different rates of wound infection have been reported, such as $2.6 \%$ [10], $6.4 \%$ [20], 8.3\% [34], 0.8\% [23], 19\% [31] and 3.6\% [35]. Although there are studies showing that the use of staplers significantly reduces the development of wound infection [20, 26, 35], there are publications claiming that the technique has no effect [23, 25]. In addition, in a clinical study published by Kim et al., they emphasized that laparoscopic endostapler repair is a safe and effective method in iatrogenic colon perforations occurring during colonoscopy [36]. In our study, our wound infection rates of $2.7 \%$ was found to be low compared to the literature. Perhaps the most important complication after laparoscopic appendectomy can be considered as IAA. We think that one of the most important reasons for this may be due to leakage after the unsafe stump closure technique. There are many studies indicating that the development of IAA is independent of the stump closure technique [6, 8, 20, 23, 25, 26, 35]. Taguchi et al. reported the rate of IAA after stapler use in complicated appendicitis as 19\% [31]. In different studies, it was found to be $11.6 \%$ [22] and 11\% [23] after laparoscopic treatment of complicated appendicitis. In our study, 5.5\% IAA was detected, and it is lower than values in the literature. We believe that 
this decrease in our infective complications is due to the safe stump closure method with a stapler.

Although it has been reported that metal staplers may cause post-operative small bowel obstruction after laparoscopic appendectomy [26, 37, 38], no patients in our study had post-operative small bowel obstruction. In our series, in which we saw post-operative ileus with a rate of $5.5 \%$, it was found to be significantly lower than that in the literature [34].

The biggest obstacle to the use of a stapler in complicated appendicitis is seen as cost $[6,7,18,23$, 34]. We believe that the total cost can be reduced by preventing post-operative complications that may occur after safe stump closure due to the use of a stapler and at the same time reducing the rate of re-hospitalization.

The limitations of our study are that it is single-centered, the number of patients is small, and the operations were performed by experienced surgeons, which may affect the results. Multi-center studies with high patient numbers are needed in the future.

\section{Conclusions}

We think that the use of a stapler is a safe and effective technique in cases where appendix base necrosis, perforation or severe inflammation in the appendix also affects the base of the cecum (stage 3B). We believe that after the safe stump closure technique, post-operative complications, duration of hospital stay and, consequently, the total cost will also decrease.

\section{Conflict of interest}

The authors declare no conflict of interest.

\section{References}

1. Golub R, Siddiqui F, Pohl D. Laparoscopic versus open appendectomy: a meta-analysis. J Am Coll Surg 1998; 186: 543-53.

2. Chung RS, Rowland DY, Li P, Diaz J. A meta-analysis of randomized controlled trials of laparoscopic versus conventional appendectomy. Am J Surg 1999; 177: 250-3.

3. So JB, Chiong EC, Chiong E, et al. Laparoscopic appendectomy for perforated appendicitis. World J Surg 2002; 26: 1485-8.

4. Wullstein C, Barkhausen S, Gross E. Results of laparoscopic vs conventional appendectomy in complicated appendicitis. Dis Colon Rectum 2001; 44: 1700-5.

5. Cueto J, D'Allemagne B, Vazquez-Frias JA, et al. Morbidity of laparoscopic surgery for complicated appendicitis: an international study. Surg Endosc 2006; 20: 717-20.
6. Rakić M, Jukić M, Pogorelić Z, et al. Analysis of endoloops and endostaples for closing the appendiceal stump during laparoscopic appendectomy. Surg Today 2013; 44: 1716-22.

7. Kliuchanok K, Keßler W, Partecke I, et al. A comparison of non-absorbable polymeric clips and staplers for laparoscopic appendiceal stump closure: analysis of 618 adult patients. Langenbeck's Arch Surg 2019; 404: 711-6.

8. Lasek A, Wysocki M, Mavrikis J, et al.; Pol-LA (Polish Laparoscopic Appendectomy) Collaborative Study Group. Comparison of stump closure techniques during laparoscopic appendectomies for complicated appendicitis - results from Pol-LA (Polish laparoscopic appendectomy) multicenter large cohort study. Acta Chir Belg 2020; 120: 116-23.

9. Mannu GS, Sudul MK, Bettencourt-Silva JH, et al. Closure methods of the appendix stump for complications during laparoscopic appendectomy. Cochrane Database Syst Rev 2017; 11: Cd006437.

10. Gomes CA, Junior CS, Costa Ede F, et al. Lessons learned with laparoscopic management of complicated grades of acute appendicitis. J Clin Med Res 2014; 6: 261-6.

11. Gomes CA, Nunes TA, Fonseca Chebli JM, et al. Laparoscopy grading system of acute appendicitis: new insight for future trials. Surg Laparosc Endosc Percutan Tech 2012; 22: 463-6.

12. Andersson RE, Hugander A, Thulin AJG. Diagnostic accuracy and perforation rate in appendicitis: association with age and sex of patient and with appendectomy rate. Eur I Surg 1998; 158: 37-41.

13. Oliak D, Yamini D, Udani V, et al. Can perforated appendicitis be diagnosed preoperatively based on admission factors? J Gastrointest Surg 2007; 4: 470-4.

14. Sauerland S, Jaschinski T, Neugebauer EA. Laparoscopic versus open surgery for suspected appendicitis. Cochrane Database Syst Rev 2010; 10: CD001546.

15. Aziz O, Athanasiou T, Tekkis PP, et al. Laparoscopic versus open appendectomy in children: a meta-analysis. Ann Surg 2006; 243: 17-27.

16. Rickert A, Bonninghoff R, Post S, et al. Appendix stump closure with titanium clips in laparoscopic appendectomy. Langenbecks Arch Surg 2012; 397: 327-31.

17. Hanssen A, Plotnikov S, Dubois R. Laparoscopic appendectomy using a polymeric clip to close the appendicular stump. JSLS 2007; 11: 59-62.

18. Matyja M, Strzałka M, Rembiasz K. Laparosocopic appendectomy, cost-effectiveness of three different techniques used to close the appendix stump. Pol Przegl Chir 2015; 87: 634-7.

19. Antoniou SA, Mavridis D, Hajibandeh S, et al. Optimal stump management in laparoscopic appendectomy: a network meta-analysis by the Minimally Invasive Surgery Synthesis of Interventions and Outcomes Network. Surgery 2017; 162: 994-1005.

20. Katsuno G, Nagakari K, Yoshikawa S, et al. Laparoscopic appendectomy for complicated appendicitis: a comparison with open appendectomy. World J Surg 2009; 33: 208-14.

21. Beldi G, Vorburger SA, Bruegger LE, et al. Analysis of stapling versus endoloops in appendiceal stump closure. Br J Surg 2006; 93: 1390-3.

22. Sahm M, Kube R, Schmidt S, et al. Current analysis of endoloops in appendiceal stump closure. Surg Endosc 2011; 25: 124-9. 
23. Van Rossem CC, van Geloven AA, Schreinemacher MH, Bemelman WA; Snapshot Appendicitis Collaborative Study Group. Endoloops or endostapler use in laparoscopic appendectomy for acute uncomplicated and complicated appendicitis: no difference in infectious complications. Surg Endosc 2017; 31: 178-84.

24. Lin HF, Lai HS, Lai IR. Laparoscopic treatment of perforated appendicitis. World J Gastroenterol 2014; 20: 14338-47.

25. Sajid MS, Rimple J, Cheek E, Baig MK. Use of endo-GIA versus endo-loop for securing the appendicular stump in laparoscopic appendicectomy: a systematic review. Surg Laparosc Endosc Percutan Tech 2009; 19: 11-5.

26. Kazemier G, in't Hof KH, Saad S, et al. Securing the appendiceal stump in laparoscopic appendectomy: evidence for routine stapling? Surg Endosc 2006; 20: 1473-6.

27. Paik PS, Towson JA, Anthone GJ, et al. Intraabdominal abscesses following laparoscopic and open appendectomies. J Gastrointest Surg 1997; 1: 188-93.

28. Miyano G, Urao M, Lane GJ, et al. A prospective analysis of endoloops and endostaples for closing the stump of the appendix in children. J Laparoendosc Adv Surg Tech A. 2011; 21: 177-9.

29. Gorter RR, Heij HA, Eker HH, Kazemier G. Laparoscopic appendectomy: state of the art. Tailored approach to the application of laparoscopic appendectomy? Best Pract Res Clin Gastroenterol 2014; 28: 211-24.

30. Poole GV. Management of the difficult appendiceal stump: how I do it. Am Surg 1993; 59: 624-5.

31. Taguchi Y, Komatsu S, Sakamoto E, et al. Laparoscopic versus open surgery for complicated appendicitis in adults: a randomized controlled trial. Surg Endosc 2016; 30: 1705-12.

32. Gomes CA, Sartelli M, Di Saverio S, et al. Acute appendicitis: proposal of a new comprehensive grading system based on clinical, imaging and laparoscopic findings. World J Emerg Surg 2015; $10: 60$.

33. Ceresoli M, Tamini N, Gianotti L, et al. Are endoscopic loop ties safe even in complicated acute appendicitis? A systematic review and meta-analysis. Int J Surg 2019; 68: 40-7.

34. Talha A, El-Haddad H, Ghazal AE, Shehata G. Laparoscopic versus open appendectomy for perforated appendicitis in adults: randomized clinical trial. Surg Endosc 2020; 34: 907-14.

35. Dimitriou I, Reckmann B, Nephuth O, Betzler M. Single institution's experience in laparoscopic appendectomy as a suitable therapy for complicated appendicitis. Langenbecks Arch Surg 2013; 398: 147-52.

36. Kim T, Kim H, Jung K, Lee S. Laparoscopic repair using an endoscopic linear stapler for management of iatrogenic colonic perforation during screening colonoscopy. Videosurgery Miniinv 2019; 14: 216-22.

37. Kuehnel F, Marusch F, Koch A, Gastinger I. Retained loose linear cutter staples after laparoscopic appendectomy as the cause of mechanical small bowel obstruction. Int J Color Dis 2007; 22: 717-8.

38. Chepla KJ, Wilhelm SM. Delayed mechanical small bowel obstruction caused by retained, free, intraperitoneal staple after laparoscopic appendectomy. Surg Laparosc Endosc Percutan Tech 2011; 21: 19-20.

Received: 22.12.2020, accepted: 6.03.2021. 